Laser Chem. 1988, Vol. 9, pp. 1-26

(C) 1988 Harwood Academic Publishers GmbH

Photocopying permitted by license only

Reprints available directly from the Publisher

Printed in the United Kingdom

\title{
Condensed Phase Laser Induced Harpoon Reactions
}

\author{
MARIO E. FAJARDO, R. WITHNALL, J. FELD, F. OKADA, \\ W. LAWRENCE, L. WIEDEMAN and V. A. APKARIAN \\ Institute for Surface and Interface Science, Department of Chemistry, \\ University of California, Irvine, California 92717
}

(Received March 28, 1988)

\begin{abstract}
Laser induced charge transfer reactions of halogens in rare gas solids and liquids provide a powerful means for the study of condensed phase dynamics. Many-body effects with respect to both electronic and nuclear coordinates, and cooperative interactions with radiation fields, are some of the studied phenomena that are highlighted in this article.

The pertinence of these ionic reactions to chemistry in solids is demonstrated in photodissociation studies of molecular halogens in rare gas matrices. The coexistence of both delocalized and localized charge transfer states in solid xenon doped with atomic halogens is presented and dynamical consequences-charge separation, self-trapping and energy storage-are discussed. Static and dynamic solvent effects in liquid phase harpoon reactions are considered. The characterization of cooperative excitationstwo-photon, two-electron transitions-in liquid solutions is presented.
\end{abstract}

KEY WORDS: $\mathrm{Xe}_{2} \mathrm{~F}, \mathrm{Xe}_{2} \mathrm{Cl}, \mathrm{Xe}_{2} \mathrm{Br}, \mathrm{Xe}_{2} \mathrm{I}, \mathrm{Kr}_{2} \mathrm{Cl}, \mathrm{Kr}_{2} \mathrm{~F}, \mathrm{KrXeCl}, \mathrm{ArXeCl}$, liquid rare gas, solid rare gas.

\section{INTRODUCTION}

Photodynamics in condensed media can be distinguished from photodynamics in the gas phase by the dominance of many-body interactions. These effects are magnified in the case of dynamics involving ionic potentials since, by virtue of the long range nature of such potentials, a reaction center cannot be isolated from the medium. Laser assisted charge transfer reactions of halogens in solid and liquid rare gases, to be discussed in this article, were designed as model 
systems in which to probe these principles. Much of this work is recent, and most of the data to be presented here is original. This field of research is far from being mature enough to warrant a full fledged review; we will rather attempt to highlight some of the more provocative results and conjectures obtained to date, with the hopes of motivating further interest and investigations in this area.

The experimental paradigm derives its origin from the well known gas phase laser assisted reactions of molecular halogens, $\mathrm{X}_{2}$, with rare gas atoms, $\mathrm{Rg}$ :

$$
\mathrm{Rg}+\mathrm{X}_{2}+\mathrm{h} v \longrightarrow\left[\mathrm{Rg}^{+} \mathrm{X}_{2}^{-}\right] \longrightarrow \mathrm{Rg}^{+} \mathrm{X}^{-}+\mathrm{X}
$$

This photo-induced harpoon reaction was originally advanced as an example of the general class of radiative collisions, ${ }^{1}$ and subsequently demonstrated in the gas phase by several investigators. ${ }^{1-5}$ The twophoton version of the same process:

$$
\mathrm{Rg}+\mathrm{X}_{2}+2 \mathrm{~h} v \longrightarrow\left[\mathrm{Rg}^{+} \mathrm{X}_{2}^{-}\right] \longrightarrow \mathrm{Rg}^{+} \mathrm{X}^{-}+\mathrm{X}
$$

has also been demonstrated in gas phase bulb experiments, ${ }^{6-8}$ and more recently in $\mathrm{Rg}: \mathrm{X}_{2}$ van der Waals complexes generated in free jet expansions..$^{9,10}$

In condensed phases the many-body scattering process of Eq. (2) can be classified under the general class of cooperative two-photon absorptions, the quantum electrodynamical formulation of which has been presented in a series of papers by Andrews et al. ${ }^{11}$ The predictable efficiency of these processes in condensed media was first demonstrated in $\mathrm{Cl}_{2}, \mathrm{HCl}$ and $\mathrm{Cl}$ doped xenon matrices, ${ }^{12,13}$ and subsequently in liquid $\mathrm{Cl}_{2} / \mathrm{Xe}$ solutions. ${ }^{14,15}$ The viability of this approach for the design of two-photon pumped, tunable condensed phase exciplex lasers was demonstrated by gain measurements in solid ${ }^{13}$ and liquid ${ }^{14}$ phase xenon chlorides, and the generalization of the principles to the entire family of xenon halides was reported. ${ }^{16}$ The liquid phase spectra of rare gas fluorides had previously been reported, ${ }^{17}$ and laser action of liquid phase exciplexes by both optical, ${ }^{18}$ and electron beam ${ }^{19}$ pumping have been demonstrated. While an understanding of the photodynamics of these ionic reactions in condensed media is crucial for such applications, our interest is more fundamentally motivated. In direct analogy with gas phase harpoon reactions, we expect the photoinduced harpoon reactions to play a significant role in advancing our understanding of condensed phase molecular dynamics. The 
selected results to be presented here are aimed at conveying this message.

The main body of this article is divided into four sections. In section II, we discuss the photodissociation dynamics of molecular halogens isolated in rare gas matrices, and contrast dissociation via the ionic potentials with those of neutral potentials. In section III, the charge transfer of rare gas solids doped with atomic halogens are presented, and the consequences of delocalization discussed. The salient aspects of this technique in unravelling classic questions in liquid phase dynamics are highlighted in section IV. Pooling together results obtained in solid and liquid phase studies, the cooperative photoexcitation process is characterized in section $\mathrm{V}$.

\section{CAGE EFFECT AND PERMANENT DISSOCIATION}

The cage effect, the process whereby the solvent prevents direct dissociation of a molecular solute and promotes geminate recombination, has been a central concept in condensed phase dynamics. A nearly perfect cage effect in solid rare gas matrices has been demonstrated by Brus, Bondybey and coworkers in their studies involving $\mathrm{ICl},{ }^{20} \mathrm{Cl}_{2},{ }^{21} \mathrm{Br}_{2},{ }^{22}$ and alkyl iodides ${ }^{23}$ in $\mathrm{Ne}, \mathrm{Ar}$, and $\mathrm{Kr}$ matrices; and in the more recent studies of Flynn and coworkers in matrix isolated $\mathrm{Br}_{2}{ }^{24}$ and $\mathrm{I}_{2}{ }^{25}$ This conclusion has been confirmed in our laboratory in the case of $\mathrm{Cl}_{2}$ in $\mathrm{Ar}$ and $\mathrm{Kr}$ matrices. The argument is as follows.

When $\mathrm{Cl}_{2}$ is promoted to its repulsive ${ }^{1} \Pi$ or ${ }^{3} \Pi$ potentials, in our case by $308 \mathrm{~nm}$ excitation, the recombinant $\mathrm{A}^{\prime} \rightarrow \mathrm{X}$ emission is observed (see Figure 1). This emission has been observed previously by Andrews $e t a l .{ }^{26}$ and subsequently reassigned by Bondybey $e t a l .{ }^{21}$ to $\mathrm{A}^{\prime}\left({ }^{3} \Pi_{2 \mathrm{u}}\right) \rightarrow \mathrm{X}\left({ }^{1} \Sigma_{\mathrm{g}}^{+}\right)$, namely: emission from the lowest excited electronic state of $\mathrm{Cl}_{2}$ to the ground state. In dilute matrices the rise of this fluorescence is prompt, and its decay is radiative. In the case of concentrated matrices in which clustering can occur, or in the case of pure solid $\mathrm{Cl}_{2}$, the fluorescence rise is slowed while the decay is accelerated, and both become multi-exponential. The most mundane observation with respect to the cage effect in dilute matrices, i.e. in the case of matrix isolated molecules, is that the intensity of this recombinant emission remains constant over long periods of irradiation. The inescapable conclusion is that the $\mathrm{Cl}$ atoms born on the repulsive 


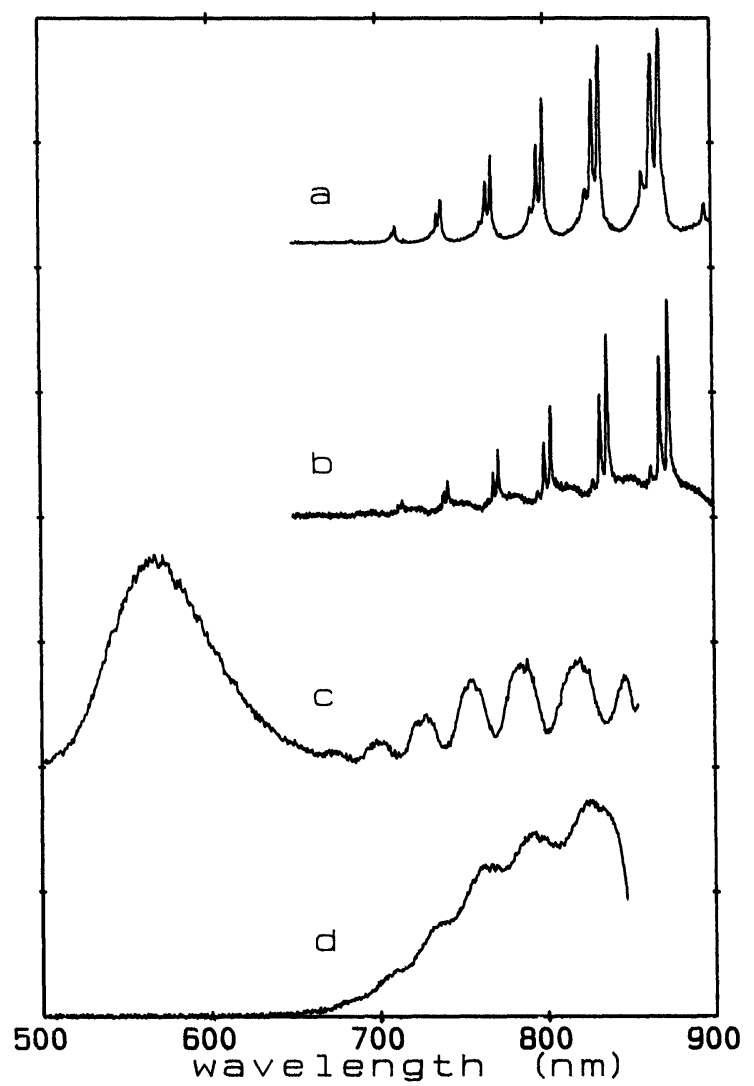

Figure $1 \mathrm{Cl}_{2}\left(\mathrm{~A}^{\prime} \rightarrow \mathrm{X}\right)$ emission spectra, $650-900 \mathrm{~nm}$, with $308 \mathrm{~nm}$ excitation at $13 \mathrm{~K}$. (a) Sample of $\mathrm{Cl}_{2}$ in Ar 1:500, 2 mmoles deposited. (b) Sample of $\mathrm{Cl}_{2}$ in $\mathrm{Kr}$ 1:500, 2 mmoles deposited. (c) Sample of $\mathrm{Cl}_{2}$ in Xe 1:500, 2 mmoles deposited. (d) Sample of pure $\mathrm{Cl}_{2}, 0.1$ mmole deposited. The spectra in (a) and (b) were recorded with a $1 / 4 \mathrm{~m}$ monochromator (20 and $40 \mu$ slits in (a) and (b) respectively). The spectra in (c) and (d) were recorded with an Optical Multichannel Analyzer, OMA, (1/3 m polychromator, with grating blazed at $450 \mathrm{~nm}, 150$ grooves $/ \mathrm{mm}$ ).

molecular potential lose their nascent kinetic energy by collisions with the repulsive wall of the cage, such that they are prevented from cage escape and hence permanent dissociation. The relaxed geminate atoms then recombine within the cage via electronic surfaces that correlate to the atomic ground state, $\mathrm{Cl}\left({ }^{2} \mathrm{P}_{3 / 2}\right)+\mathrm{Cl}\left({ }^{2} \mathrm{P}_{3 / 2}\right)$. There are subtle cage effects that determine the dominance of one surface over 
others during recombination, ${ }^{24,25}$ however the gross effect, which seems to be validated by all studies, is that the cage induces nearly $100 \%$ recombination in these low temperature matrices.

The $\mathrm{Cl}_{2}\left(\mathrm{~A}^{\prime} \rightarrow \mathrm{X}\right)$ emission has been monitored in our studies over extended periods of exposure, $>10^{5}$ pulses at $308 \mathrm{~nm}$ with pulse fluences exceeding $50 \mathrm{~mJ} / \mathrm{cm}^{2}$, yet no noticeable $( \pm 5 \%)$ diminution in emission intensity could be seen. Two conclusions are to be derived: that permanent dissociation probabilities are very small, and that the methodology is not sensitive enough to monitor very small dissociation cross sections. The latter conclusion is based on the fact that matrices prepared by vapor deposition of gaseous samples on a cooled substrate are far from being perfectly crystalline; hence molecular dissociation near defects such as incomplete trapping cages, should occur. The presence of this minor dissociative channel can be verified by thermoluminescence spectroscopy. After extensive irradiation of $\mathrm{Cl}_{2}$ doped matrices at low temperatures, $12 \mathrm{~K}$, the recombinant $\mathrm{A}^{\prime} \rightarrow \mathrm{X}$ emission is observed during warm-up of the samples (see Figure 2a). The emission is weak and persists for the duration of the warm-up, however most of the recombination is complete by $\sim 25 \mathrm{~K}$. The intensity of this thermoluminescence depends on the thermal history of the solid. From the known absorption coefficients of $\mathrm{Cl}_{2}$ at $308 \mathrm{~nm}$, it can be estimated that the quantum yield for permanent dissociation for isolated molecules is less than $10^{-6}$. It should however be clear from the above that dissociation, or at least delayed recombination occurs at imperfections, in clusters, and in the molecular solid.

A very different situation arises in the case of dissociation via ionic potentials. Such a channel is available to $\mathrm{Cl}_{2}$ isolated in solid xenon when irradiated in the near UV. While significantly broadened, the $\mathrm{Cl}_{2}\left(\mathrm{~A}^{\prime} \rightarrow \mathrm{X}\right)$ vibrational progression can be clearly observed in these solids when excited at $308 \mathrm{~nm}$ (see Figure 1c). However in this case it is not possible to prevent permanent dissociation-the excitation fluences necessary for observing the emissions, $\sim 100 \mu \mathrm{J} / \mathrm{cm}^{2}$ per pulse, are also sufficient to cause their disappearance in time. Along with the disappearance of this far red emission, a bright yellow emission centered at $573 \mathrm{~nm}$ due to $\mathrm{Xe}_{2}^{+} \mathrm{Cl}^{-}\left(4^{2} \Gamma \rightarrow 1,2^{2} \Gamma\right)$ grows in time (see spectrum in Figure 1c). The disappearance of the $\mathrm{A}^{\prime} \rightarrow \mathrm{X}$ emission and concomitant growth of the exciplexic emission are illustrated in Figure 3. This situation has been found to be true for all studied halogens- $\mathrm{Cl}_{2}, \mathrm{~F}_{2}, \mathrm{Br}_{2}, \mathrm{ICl}$-and all hydrogen halides in solid xenon. 


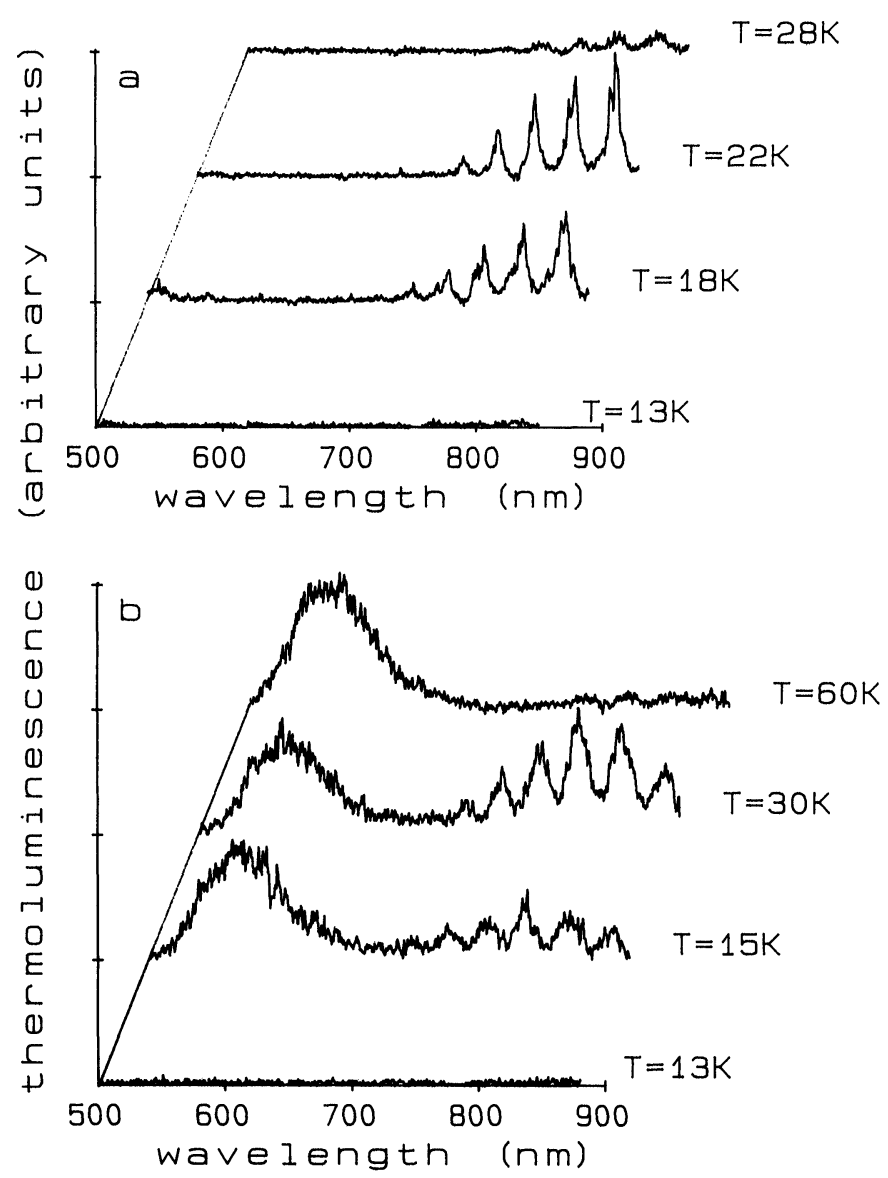

Figure 2 Thermoluminescence spectra recorded during warmup of matrices doped with $\mathrm{Cl}_{2}$, after extensive irradiation at $308 \mathrm{~nm}$. Emission detected with OMA, corresponding temperatures are indicated. (a) Sample of $\mathrm{Cl}_{2}$ in $\mathrm{Kr}$ 1:500, 2 mmoles deposited; heating rate of $\sim 1.7 \mathrm{~K} / \mathrm{s}, 1$ second averaging time per spectrum. (b) Sample of $\mathrm{Cl}_{2}$ in $\mathrm{Xe}$ $1: 500,2$ mmoles deposited; heating rate of $\sim 0.5 \mathrm{~K} / \mathrm{s}, 10$ second averaging time per spectrum.

With the exception of $\mathrm{F}_{2}$ doped xenon, in all cases the triatomic $\mathrm{Xe}_{2}^{+} \mathrm{X}^{-}$ emissions are seen to grow with irradiation time. In the case of $F_{2}$, the triatomic exciplex emission initially grows and subsequently falls with exposure time. The obvious cause of the disappearance in this case is the formation of the stable covalently bonded xenon fluorides- $-\mathrm{XeF}_{2}$, 


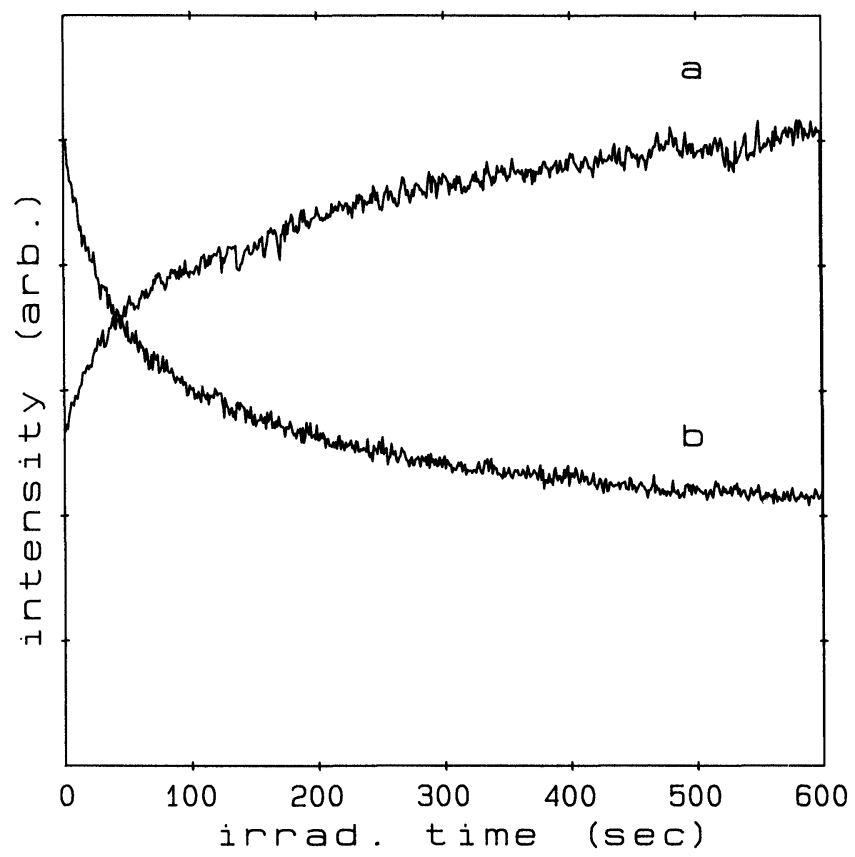

Figure 3 Permanent dissociation of $\mathrm{Cl}_{2}$ in solid xenon irradiated at $308 \mathrm{~nm}$, as a function of irradiation time $\left(1: 500 \mathrm{Cl}_{2}\right.$ :Xe solid at $\left.13 \mathrm{~K}\right)$. (a) Growth of the $570 \mathrm{~nm}$ $\mathrm{Xe}_{2} \mathrm{Cl}$ exciplexic emission intensity. (b) Decrease of the $\mathrm{Cl}_{2}\left(\mathrm{~A}^{\prime} \rightarrow \mathrm{X}\right)$ recombinant emission intensity at $800 \mathrm{~nm}$ in the same sample.

$\mathrm{XeF}_{4}$-which are stable with respect to irradiation at $308 \mathrm{~nm}$. The spectroscopy of the exciplexes and detailed kinetic analysis of growth curves has been presented previously, ${ }^{12}$ the model that emerges can be summarized as:

$$
\begin{aligned}
& \mathrm{Rg}+\mathrm{X}_{2}+2 \mathrm{~h} v \longrightarrow\left[\mathrm{Rg}^{+} \mathrm{X}_{2}^{-}\right] \longrightarrow \mathrm{Rg}^{+} \mathrm{X}^{-}+\mathrm{X} \\
& \mathrm{Rg}^{+} \mathrm{X}^{-} \stackrel{\mathrm{Rg}}{\longrightarrow} \mathrm{Rg}_{2}^{+} \mathrm{X}^{-}
\end{aligned}
$$

The first step is the two-photon induced harpoon reaction which results in the ejection of a neutral halogen atom out of the trap cage. The second step, namely the reactive quenching of the diatomic to form the triatomic exciplex, is fast and proceeds on the timescale of $\sim 10^{-12} \mathrm{~s}$, such that no diatomic $\mathrm{B} \rightarrow \mathrm{X}$ emission is observed. When the excita- 
tion energy is above the solid state $\mathrm{B} \leftarrow \mathrm{X}$ absorption threshold of the diatomic exciplexes, the isolated atomic halogens will undergo onephoton charge transfer and subsequently form the triatomic, viz:

$$
\mathrm{Rg}+\mathrm{X}+\mathrm{h} v \longrightarrow \mathrm{Rg}^{+} \mathrm{X}^{-} \stackrel{\mathrm{Rg}}{\longrightarrow} \mathrm{Rg}_{2}^{+} \mathrm{X}^{-}
$$

The reaction progress is followed by monitoring the radiative dissociation of the triatomic exciplex:

$$
\mathrm{Rg}_{2}^{+} \mathrm{X}^{-} \longrightarrow \mathrm{Rg}+\mathrm{Rg}+\mathrm{X}+\mathrm{h} v^{\prime}
$$

This scheme, the combination of Eqs. (4) and (5), constitutes a technique for near unity quantum yield detection of atomic halogens isolated in rare gas solids. The analysis of growth curves by this kinetic model has yielded cross sections for the two-photon, minimally four body transition represented by Eq. (1) in solids. Using these cross sections, and the observed fractional disappearance of the recombinant $\mathrm{A}^{\prime} \rightarrow \mathrm{X}$ emission, it can be estimated from initial rates of growth of the exciplexic emissions that the quantum yield of permanent dissociation is near unity. The process however saturates. A turnover in growth curves is observed which can be ascribed to the screening of the excitation energy by the atomic charge transfer absorptions of Eq. (4), and by the increased optical scattering of the solids due to amorphization caused by kinetic energy release in the radiative dissociation of Eq. (5). Attempts at driving the dissociation to completion in matrices of $M / R<5000$ have failed-the ablation limit of the solid is reached prior to atomization of all molecular dopants.

This situation is not limited to xenon. The same observations can also be made in the lighter rare gas solids, provided the excitation wavelength is short enough to effect both the two-photon harpoon transition and the subsequent atomic charge transfer. This can be achieved in $\mathrm{Cl}_{2}: \mathrm{Kr}$ samples by irradiation at $225 \mathrm{~nm}$. The only observed emission in this case is that of $\mathrm{Kr}_{2} \mathrm{Cl}\left(4^{2} \Gamma \rightarrow 1,2^{2} \Gamma\right)$ shown in Figure 4. This emission intensity grows with irradiation time with a growth curve characteristic of two-photon induced chemistry (see inset to Figure 4). As in the case of all other exciplexes, the fluorescence rise follows the laser pulse and relaxes radiatively. The radiative lifetime in this case is $360 \mathrm{~ns}$, comparable to the lifetime of the xenon halides in solid xenon (see Table I). The absence of any molecular $\mathrm{Cl}_{2}$ emissions, in particular the $\mathrm{A}^{\prime} \rightarrow \mathrm{X}$ emission, in this case is quite significant. 


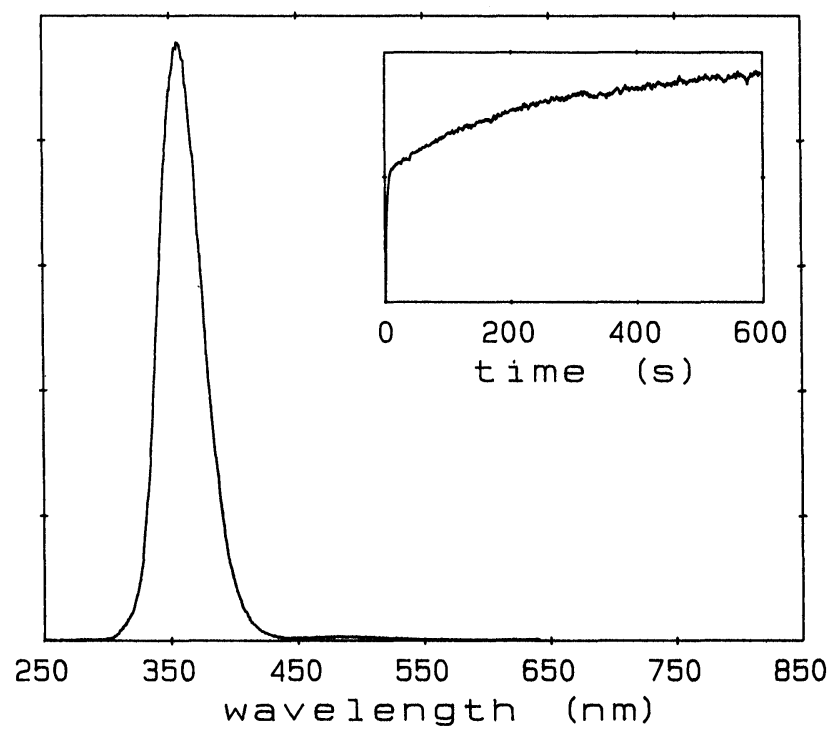

Figure $4 \mathrm{Kr}_{2} \mathrm{Cl}\left(4^{2} \Gamma \rightarrow 1,2^{2} \Gamma\right)$ exciplexic emission with $225 \mathrm{~nm}$ excitation at $13 \mathrm{~K}$. Sample of $\mathrm{Cl}_{2}$ in $\mathrm{Kr}$ 1:500, 2 mmoles deposited. Inset shows growth of the $356 \mathrm{~nm}$ emission intensity in the same sample as a function of irradiation time. The ordinates in Figures 4-8 are emission intensities in arbitrary units.

Table I Spectroscopic data for X atom doped solid Xe.

\begin{tabular}{lllll}
\hline & $\mathrm{X}: \mathrm{Xe}$ absorption & & $\mathrm{Xe} \mathrm{e}_{2} \mathrm{X}$ emissions \\
\cline { 1 - 2 } \cline { 5 - 5 } $\mathrm{X}$ & $\lambda \max (\mathrm{nm})$ & & $\lambda \max (\mathrm{nm})$ & $\tau(\mathrm{nsec})$ \\
\hline $\mathrm{F}$ & 352 & 775 & 190 \\
$\mathrm{Cl}$ & $\mathrm{a} 332(\mathrm{~s})$ & $355(\mathrm{i})$ & 573 & 225 \\
$\mathrm{Br}$ & 308 & 480 & 185 \\
$\mathrm{I}$ & 279 & 390 & 130 \\
\hline
\end{tabular}

a Substitutional trapping site, (i): interstitial trapping site.

Two-photon excitation of $\mathrm{Cl}_{2}$ at $225 \mathrm{~nm}$ could in principle lead to population of the excited molecular Rydberg states, and subsequent access of the ion-pair states. However, no $\mathrm{D}^{\prime} \rightarrow \mathrm{A}^{\prime}$ emission is observed. An implication is that if any $\mathrm{Cl}_{2}$ molecular states are excited, they are strictly reactive - they do not lead to population of the $\mathrm{A}^{\prime}$ state by emission. While the exact steps involved in the access of the $\mathrm{Cl}_{2}$ ion-pair states is controversial, emission from the lowest surface of 
this manifold, the $\left(\mathrm{D}^{\prime} \rightarrow \mathrm{A}^{\prime}\right)$ emission, has been observed in $\mathrm{Ar},{ }^{27}$ $\mathrm{Kr},{ }^{28}$ and $\mathrm{Ne}^{29,30}$ matrices. This would imply that at least $\mathrm{Cl}_{2}\left(\mathrm{D}^{\prime}\right)$, and all other states involved in the relay of population to the ion-pair manifold in those experiments, are not reactive with $\mathrm{Kr}$. Thus the absence of any molecular chlorine emissions, and the observation of efficient growth in the $\mathrm{Kr}_{2} \mathrm{Cl}\left(4^{2} \Gamma\right)$ emission strongly argue that the two-photon laser driven reactions in the present are due mainly to intermolecular charge transfer excitations that lead to harpooning with the ejection of neutral halogens, Eq. (2). The extent of subsequent atomic recombination is evidently minor-the expected $\mathrm{Cl}_{2}\left(\mathrm{~A}^{\prime} \rightarrow \mathrm{X}\right)$ emission is below our detection threshold in this case. It can safely be concluded then that permanent dissociation is efficient.

The main conclusion that we would like to impress from the above discussion is that the perfect cage effect experienced by molecules undergoing photodissociation via neutral potentials is absent in the case of dissociation via the ionic potentials involved in the harpoon mechanism. The latter does lead to permanent dissociation, and hence to chemistry in solids. These are consequences of dynamics controlled by many-body interactions. Their full understanding will require a serious theoretical effort. Molecular Dynamics simulations, in progress at present, may provide an important first step toward this goal. In the absence of such rigorous analysis, we provide a simple intuitive picture to explain these differences and advance the postulate of a "negative" cage effect.

In the simplest of pictures, the normal cage effect can be understood by reference to two coordinates: the internuclear coordinate of the molecular halogen, and a molecule-cage configurational coordinate. Photodissociation via neutral potentials is initiated by the localized excitation of the molecular coordinate-a sudden switch of this potential from deeply bound to strictly repulsive. The molecule-cage potential remains intact. Collisions with the repulsive wall of the potential along this coordinate result in the loss of recoil energy, and subsequent geminate recombination. In the case of liquids, or small clusters, the repulsive wall may be softened in selected geometric directions, and hence the recombination probability may be less than unity. However in the case of crystalline solids a head-on collision, and hence a strictly repulsive wall in all directions cannot be avoided.

In the case of the photo-induced harpoon reaction, both molecular and molecule-cage potentials are suddenly switched by the radiation 
field. The vertical transition from $\mathrm{X}_{2}$ to $\mathrm{X}_{2}{ }^{-}$creates the ion on the repulsive part of its potential. The potential along the molecule-cage coordinate in this case becomes attractive, since it represents the interaction of a negatively charged molecular ion and a positively charged cage. A transition state can then be imagined in which the charges are localized on nearest neighbor atoms, $\mathrm{Rg}^{+} \cdots \mathrm{X}^{-} \cdots \mathrm{X}$, while the rest of the cage atoms are polarized and hence attracted to the ionic moiety. A stretch of the repulsive $X^{-} \ldots X$ molecular coordinate in concert with the collapse of the cage around the dipolar exciplex completes the dissociation. The exciplex is further stabilized by localizing in the triatomic $\operatorname{Rg}_{2}^{+} \mathrm{X}^{-}$configuration. The ejected $\mathrm{X}$ atom is then prevented from cage reentry for the duration of the exciplexic radiative lifetime, $\sim 10^{-7} \mathrm{~s}$, during which time all memory of its nascence would be lost.

The postulated active role of the cage in promoting permanent dissociation in the above scenario is referred to as the negative cage effect, and is thought to be necessary in accounting for the inordinate efficiency of harpoon reactions in condensed media.

\section{CHARGE TRANSFER STATES OF RGS DOPED WITH ATOMIC HALOGENS}

Emission spectra of matrix isolated rare gas halides were first reported by Andrews $e t$ al. ${ }^{31}$ In a recent paper we have discussed the spectroscopy of all triatomic xenon halides. ${ }^{32}$ These studies have been extended to the kypton halides as well. Examples of such spectra were shown in Figures $1 \mathrm{c}$ and 4 , for $\mathrm{Xe}_{2} \mathrm{Cl}$ and $\mathrm{Kr}_{2} \mathrm{Cl}$ respectively. The emission maxima and radiative lifetimes of the triatomic xenon halides in solid xenon are collected in Table I. These spectra are recorded on the timescale of radiative lifetimes, $\sim 10^{-7} \mathrm{~s}$, and hence correspond to fully relaxed charge transfer states. The observed emission profiles can be adequately fitted by the known gas phase potentials of these species, after making due allowance for the shift of the ionic upper state due to the dielectric of the solid. In short, these relaxed charge transfer states correspond to localized molecular exciplexes isolated in the solid matrix.

The harpoon mechanism discussed in the previous section consti- 
tutes a useful method for preparing RGS doped with atomic halogens. This approach to sample preparation has been followed by us in studies of excitation spectra; namely of the vertically accessed charge transfer states of solid xenon doped with all atomic halogens. We note that, with the exception of $F$ doped xenon, all other solids can be annealed without significant recombination of the halogen atoms. In the case of $\mathrm{F}$ doped solids permanent loss of the exciplexic emission is observed upon each annealing cycle, presumably due to the formation of the stable covalently bonded xenon fluorides. The same observation is also made in the liquid phase and will be further discussed in the next section. Since annealing is possible, we may conclude that the surviving halogen atoms are separated by several lattice sites. Moreover, annealing enables the preparation of halogen atoms isolated in crystalline environments. Due to the conceptual simplicity of these systems, the description of their charge transfer states has already provoked substantial theoretical interest. ${ }^{33-36}$ Here we will only present a succinct discussion of the relevant results, for the most recent detailed discussions see Refs. 32 and 37.

It is now clear that the vertically accessed charge transfer states of solid xenon doped with atomic halogens (F may be an exception) are delocalized: an electron trapped on the halogen atom and a hole delocalized over the extended solid. This conclusion can be reached starting from either a molecular model, or from an excitonic model for the description of the charge transfer states. The molecular formalism is based on the semiempirical theory of Diatomics in Ionic Systems developed for the expressed purpose of treating this problem. ${ }^{34}$ In this model, the halogen atom and its nearest neighbor xenons are considered explicitly, while the rest of the solid is treated as a dielectric continuum. The charge transfer states of the cluster, halogen atom and cage atoms, are then calculated by linear combinations of the valence atomic orbitals. It is shown that the Franck-Condon accessed charge transfer states of the complex are delocalized, while the minimum energy configuration of the system closely resembles the gas phase triatomic $\mathrm{Xe}_{2}^{+} \mathrm{Cl}^{-}$configuration. The localization of excitation is then to be expected since the inter-xenon distance in the exciplex is more than an Angstrom shorter than the nearest neighbor distance in crystalline xenon at $10 \mathrm{~K} .{ }^{12}$

An alternate approach to this problem starts by treating the photoinduced charge transfer as the creation of an electron localized on the 
halogen atom and a valence band hole. The hole wavefunction is constructed as a wavepacket from the Bloch states of the valence band. This description allows for the creation of electron-hole pairs separated by several lattice sites. The excitation spectra can then be treated as a reflection of the local radial distribution function from the screened interpolaronic potential. This formalism has been used for the interpretation of the structured excitation spectra obtained in well annealed $\mathrm{Cl}, \mathrm{Br}$, and $\mathrm{I}$ doped xenon. ${ }^{32}$ Such spectra then serve as a direct probe of local structure and many-body potentials-potentially a very powerful technique for the investigation of condensed phase energetics. It is important to note that the excitation thresholds in these solids correspond to the transfer of an electron from a nearest neighbor xenon to the halogen atom; as such they derive their origins directly from the diatomic $\mathrm{XeCl}(\mathrm{B} \leftarrow \mathrm{X})$ transitions. The maxima of the first absorption peaks for the different halogens in solid xenon are also collected in Table $\mathrm{I}$.

The excitonic description also allows the interpretation of energy storage, thermoluminescence and phosphorescence, observed in these atomic solids. An example of the thermoluminescence was shown in Figure $2 b$ in which, besides the recombinant $A^{\prime} \rightarrow X$ emission, the $\mathrm{Xe}_{2}^{+} \mathrm{Cl}^{-}$emission is observed. The observation of this thermoluminescence from the charge transfer complex $\mathrm{Xe}_{2}^{+} \mathrm{Cl}^{-}$implies that the energy is stored by charged species-a negatively charged halide ion and a self-trapped hole. These polaronic species are stable with respect to recombination at $12 \mathrm{~K}$-thermoluminescence as long as $35 \mathrm{hrs}$ after the initial irradiation has been observed at this temperature. Thus the creation of delocalized charge transfer states, and the subsequent charge separation by self-trapping serve as a scheme of optical energy storage. Stored charge densities as high as $10^{17} \mathrm{~cm}^{-3}$ have been observed in $\mathrm{Br}$ doped xenon. ${ }^{37}$ The thermoluminescence curves have been analyzed by kinetic treatment of the ion-hole recombination to obtain detrapping barriers and frequency factors - a barrier height of $0.11 \mathrm{eV}$ and a frequency factor of $10^{9( \pm 1)} \mathrm{s}^{-1}$ is obtained for releasing the self-trapped hole in xenon. ${ }^{37}$ In contrast with the older calculations, ${ }^{38}$ in which self trapped holes in xenon were assumed to be $\mathrm{Xe}_{2}^{+}$ and estimated to be bound by $0.5 \mathrm{eV}$; the most recent calculations ${ }^{39}$ placed the depth at $0.0 \mathrm{eV}$, i.e. within the errors in the calculation localization could not be reliably predicted. However in lighter rare gases the self trapped states are deeper and in all cases the $\mathrm{Rg}_{3}^{+}$ 
configuration is preferred over $\operatorname{Rg}_{2}^{+}$as the more stable trapping site for a hole. ${ }^{39}$

The coexistence of both localized and delocalized charge transfer states in these simple atomic solids makes them model systems for the study of condensed phase charge transfer processes-charge separation, mobility, trapping and recombination. A global picture of potentials, essential for the understanding of these phenomena, is now emerging. It may also be surmised that if the negative halogen ion is replaced by a molecular ion, then ion-hole recombination (induced by thermal shock) may constitute a powerful spectroscopic technique for obtaining neutralization spectra of unstable isolated negative ions in solids.

\section{LIQUID PHASE EXCIPLEXES AND PHOTO-INDUCED HARPOONING}

Two-photon excitation of liquid solutions of molecular halogens in rare gases results in the formation of the molecular exciplexes. When a single component rare gas solvent is used, only the triatomic exciplexes are observed. The emission spectra of the triatomic xenon halides in liquid xenon are shown in Figure 5. The emissions are characteristically broad due to the bound-free nature of transitions. They all undergo large spectral shifts relative to their gas phase counterparts due to the ionic-covalent nature of transitions. The latter consideration makes these systems ideal for the study of solvation dynamics, in particular since these exciplexes are long lived in the liquid phase-in dilute solutions the relaxation is dominated by radiation; in concentrated solutions the relaxation is due to diffusion controlled encounters of the exciplex with the parent molecular halogen. ${ }^{15}$ It is important to point out that with the exception of $\mathrm{Xe}_{2} \mathrm{~F}$, all of these emissions are stable with respect to duration of excitation. In contrast with the low temperature matrices, in the liquids the halogen atoms are free to recombine between excitation pulses. In the case of solutions of $F_{2}$ in either xenon or krypton, the exciplexic emissions quickly disappear with irradiation time. The triatomic $\mathrm{Kr}_{2} \mathrm{~F}$ emission, obtained by $280 \mathrm{~nm}$ irradiation of $F_{2} / \mathrm{Kr}$ solutions, is shown in Figure 6 . The disappearance of the exciplexic emission as a function of irradiation time is illustrated in the inset to Figure 6. This is an expected result based on the known stability of the covalently bonded xenon and 


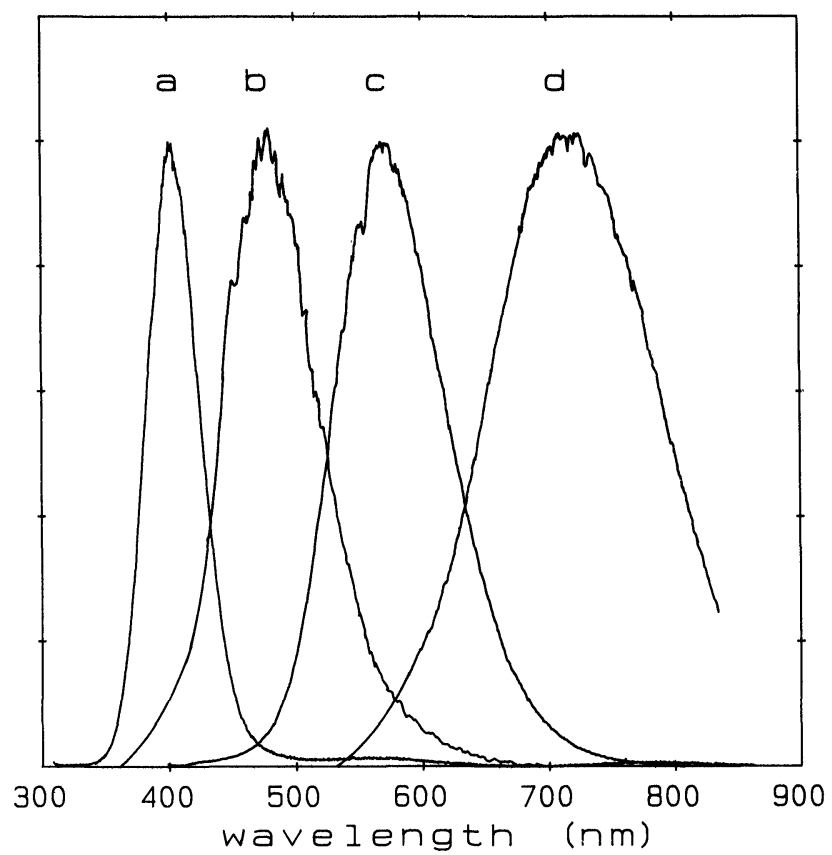

Figure 5 Emission spectra of the triatomic xenon halides, (a) $\mathrm{Xe}_{2} \mathrm{I}$, (b) $\mathrm{Xe}_{2} \mathrm{Br}$, (c) $\mathrm{Xe}_{2} \mathrm{Cl}$, (d) $\mathrm{Xe}_{2} \mathrm{~F}$, in liquid xenon; obtained by $308 \mathrm{~nm}$ irradiation of $\mathrm{F}_{2}, \mathrm{Cl}_{2}$ and $\mathrm{Br}_{2}$ solutions in liquid xenon. The iodide emission is from an $\mathrm{HI} / \mathrm{Xe}$ solution excited at $280 \mathrm{~nm}$. The spectra are recorded with an OMA with a detection cutoff at $850 \mathrm{~nm}$.

krypton fluorides, $\mathrm{XeF}_{2}$ and $\mathrm{KrF}_{2}$ in particular. The stability of the $\mathrm{Xe}_{2} \mathrm{Cl}$ emission with irradiation time would indicate that the covalently bonded xenon chlorides are not stable, and do not form in the liquid phase. This result has been further verified by recording absorption spectra in the liquid cell prior to irradiation of the solution, and after extensive irradiation ( $>20,000$ pulses, $\sim 200 \mathrm{~mJ} / \mathrm{pulse})$ at $351 \mathrm{~nm}$, a wavelength near the maximal efficiency of $\mathrm{Xe}_{2} \mathrm{Cl}$ production (vide infra)-neither are new absorption features observed nor does the $\mathrm{Cl}_{2}$ absorption diminish. This result raises questions about matrix spectra previously assigned ${ }^{40}$ to $\mathrm{XeCl}_{2}$.

In the case of molecular halogens dissolved in two-component rare gas solvents, emissions due to the diatomic exciplexes and the mixed triatomic exciplexes can be observed. Two examples are presented in 


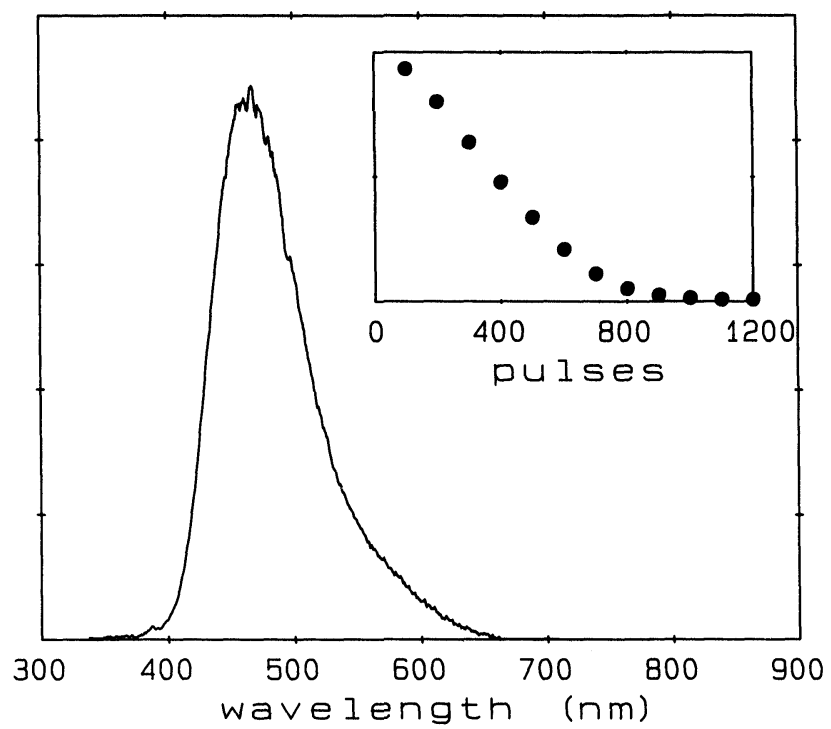

Figure $6 \mathrm{Kr}_{2} \mathrm{~F}$ exciplexic emission obtained by $280 \mathrm{~nm}$ excitation of $\mathrm{F}_{2}$ in liquid krypton. The inset shows the disapppearance of this emission with laser irradiation.

Figures 7 and 8. The spectrum in Figure 7 is from a solution of $\mathrm{Cl}_{2} / \mathrm{Xe} / \mathrm{Kr}$. While the triatomic xenon chloride can be observed, the diatomics are absent and the main emission is due to $(\mathrm{XeKr})^{+} \mathrm{Cl}^{-}$. The spectrum in Figure 8 is from a solution of $\mathrm{Cl}_{2} / \mathrm{Xe} / \mathrm{Ar}$. The diatomic $\mathrm{B} \rightarrow \mathrm{X}$ and $\mathrm{C} \rightarrow \mathrm{A}$ emissions are clearly visible in addition to the triatomic xenon chloride. Based on concentration and temperature dependence studies, the peak at $480 \mathrm{~nm}$ can be assigned to $(\mathrm{XeAr})^{+} \mathrm{Cl}^{-}$. The diatomic and mixed triatomic excipleses in this case are in dynamic equilibrium:

$$
\mathrm{Ar}+\mathrm{Xe}^{+} \mathrm{Cl}^{-} \rightleftharpoons(\mathrm{XeAr})^{+} \mathrm{Cl}^{-}
$$

Both emissions disappear due to diffusion controlled reaction of the diatomic with xenon to form the symmetric triatomic xenon chloride. The equilibrium in Eq. (6) is favored toward the mixed triatomic as the temperature of the solution is lowered. In the case of $\mathrm{Kr}$, clearly the mixed triatomic is substantially more stable such that diatomics are reactively quenched by the solvent without having the chance to radiate. As expected, the stability of the mixed triatomics is dictated by 


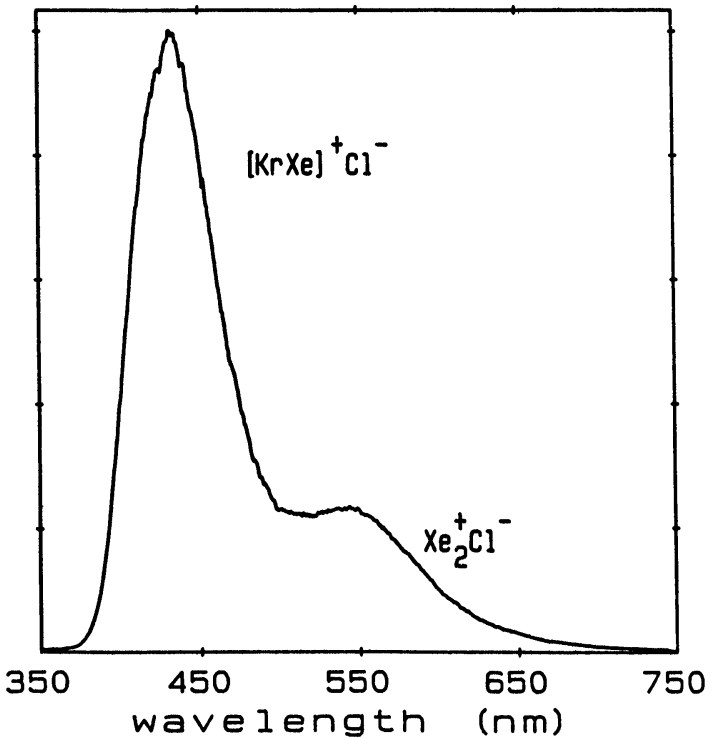

Figure 7 Emission spectrum obtained with $308 \mathrm{~nm}$ excitation of a solution of $0.1 \mathrm{mM}$ $\mathrm{Cl}_{2}, 1 \mathrm{mM} \mathrm{Kr}$ in liquid xenon at $165 \mathrm{~K}$.

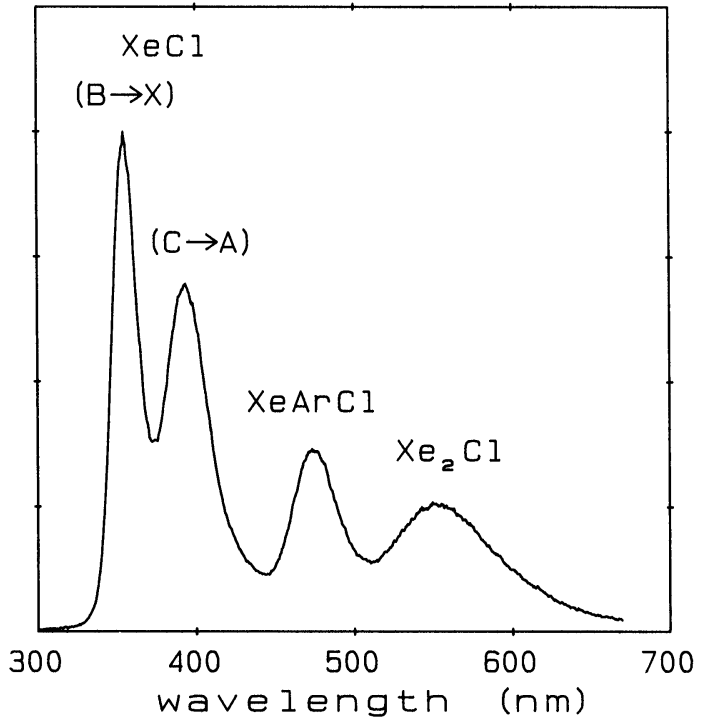

Figure 8 Emission spectrum obtained with $308 \mathrm{~nm}$ excitation of a solution of $2.8 \mathrm{mM}$ $\mathrm{Cl}_{2}, 5.4 \mathrm{mM} \mathrm{Xe}$ in liquid $\mathrm{Ar}$ at $85 \mathrm{~K}$. 
the disparity between the sizes of the rare gas atoms involved. The relative emission intensities of the diatomics, triatomics, and mixed triatomics in these liquid phase spectra are a sensitive function of temperature and concentration, and quite different from the matrix spectra of halides in mixed rare gas hosts. ${ }^{12}$ The observed energetic stability of the different exciplexes in the liquid phase is also bound to be different from the energetics in the gas phase. The main difference is the solvation of these large dipoles by the polarizable solvent atoms. We have recently shown that the exciplexes in solution are strongly clustered; in effect, a cage tighter than that of crystalline environments is created in the liquid phase. ${ }^{41,42}$ Moreover, the solvent cage lends dynamic stability to the exciplex which was recently demonstrated in studies of $\mathrm{ICl}$ in liquid xenon. ${ }^{41} \mathrm{In}$ the case of $\mathrm{ICl} / \mathrm{Xe}$ solutions where both $\mathrm{Xe}_{2} \mathrm{I}$ and $\mathrm{Xe}_{2} \mathrm{Cl}$ are observed, both triatomics are observed to relax with the same fluorescence lifetime $(\sim 100 \mathrm{~ns}$ under the particular experimental conditions) ${ }^{41}$ Given the fact that the chloride is more stable than the iodide by nearly one $\mathrm{eV}$, and that for every iodide created from $\mathrm{ICl}$ there necessarily is a geminately created $\mathrm{Cl}$ atom in near proximity, the absence of the exchange reaction:

$$
\mathrm{Xe}_{2}^{+} \mathrm{I}^{-}+\mathrm{Cl} \longrightarrow \mathrm{Xe}_{2}^{+} \mathrm{Cl}^{-}+\mathrm{I}
$$

could only be rationalized as due to the shielding of the exciplex by a solvent cage composed of the polarizable $\mathrm{Xe}$ atoms at the exclusion of the $\mathrm{Cl}$ atom. Further evidence for the existence of a tight solvent cluster is given by lineshift arguments most convincingly observed in studies of $\mathrm{HI}$ in liquid and crystalline solid xenon. ${ }^{42}$

Quite clearly the photo-induced charge transfer reactions of halogens in rare gas liquids provide an opportunity for the study of detailed molecular dynamics in the liquid phase. The reactions of interhalogens are particularly useful for this purpose since they provide the additional observable of product branching ratios-a powerful handle on the potential hypersurfaces involved in the reactive dynamics. A very significant wavelength dependent control of branching ratios has been demonstrated in the case of $\mathrm{ICl} / \mathrm{Xe}$ solutions. ${ }^{41}$ The analogy between these studies and classic harpoon reactions is straightforward-it may be argued that the liquid phase is the more natural medium for harpooning. An understanding of the optical resonances, which serve as the reaction entrance channel in this case, is crucial for the interpre- 
tation of results and generalization of the methodology. These are considered in the next section.

\section{EXCITATION RESONANCES}

In solutions of the molecular halogens, $\mathrm{F}_{2}, \mathrm{Cl}_{2}$ and $\mathrm{Br}_{2}$ in liquid xenon, a very intense absorption edge which originates near $200 \mathrm{~nm}$ is observed. ${ }^{43}$ The absorption occurs near the instrumental cutoff of the standard u.v.-vis. spectrometer used, and therefore has not been fully characterized experimentally. Based on the intensity of this absorption, it can be confidently assigned to the contact charge transfer between xenon and the molecular halogen: $\mathrm{Xe}^{+}\left({ }^{3} \mathrm{P}\right): \mathrm{X}_{2}^{-}\left({ }^{2} \Sigma_{\mathrm{u}}^{+}\right)$ $\leftarrow \mathrm{X}\left({ }^{1} \mathrm{~S}_{\mathrm{o}}\right): \mathrm{X}_{2}\left({ }^{1} \Sigma_{\mathrm{g}}\right)$. The observed absorption energy could be rationalized based on simple estimates of Coulombic bonding and solvation of the ion-pair in the polarizable medium. These absorptions are expected to be broad primarily due to the breadth of vertical electron affinities of molecular halogens. The expected lineshapes have been presented. ${ }^{43}$

Irradiation of $\mathrm{Cl}_{2} / \mathrm{Xe}$ solutions within this band, with the $193 \mathrm{~nm}$ output of an ArF laser, results in the efficient formation of $\mathrm{Xe}_{2} \mathrm{Cl}$. The exciplex emission intensity at this wavelength has a one-photon fluence dependence. The efficiency of dissociative charge transfer, harpooning with the ejection of a $\mathrm{Cl}$ atom, can be expected to be strongly wavelength dependent over the profile of this contact charge transfer absorption. This expectation is based on the fact that the $\mathrm{v}=\mathrm{o}$ wavefunctions of the molecular halogens, $\mathrm{X}_{2}$, span the repulsive wall of the $X_{2}^{-}$ions at internuclear distances that range from the bound ion to several $\mathrm{eV}$ above its dissociation limit. Thus a vertical transition from the right turning point of $X_{2}(v=o)$ can lead to the formation of an $\mathrm{Xe}^{+} \mathrm{X}_{2}^{-}$complex that can be further stabilized by the solvent; while a transition from the left turning point should lead to strictly dissociative charge transfer. The latter situation should prevail in the case of accessing $\mathrm{X}_{2}^{-}$(П) states which are purely repulsive. Thus efficient production of the exciplexes should be expected in the deeper UV. Due to the unavailability of convenient light sources, this spectral range has not yet been investigated directly. However, given the large cross sections of these transitions in the condensed phase, they can be accessed by two-photon excitation-the technique that we have relied on in most of our studies. 
Two-photon excitation spectra have been obtained in $\mathrm{Br}_{2}, \mathrm{Cl}_{2}$ and $\mathrm{ICl}$ solutions in liquid xenon. A typical example is shown in Figure 9 for the case of $\mathrm{Br}_{2}$. The excitation is featureless, however clearly shows a two-photon dependence. Fluence dependence measurements have been performed at several discrete wavelengths between 330 and $372 \mathrm{~nm}$ to verify the second order nature of the excitation. This range of wavelengths is significant in that it corresponds to a spectral range well removed from the condensed phase $\mathrm{XeBr}(\mathrm{B} \leftarrow \mathrm{X})$ absorption i.e., the atomic charge transfer transition. (The latter was obtained
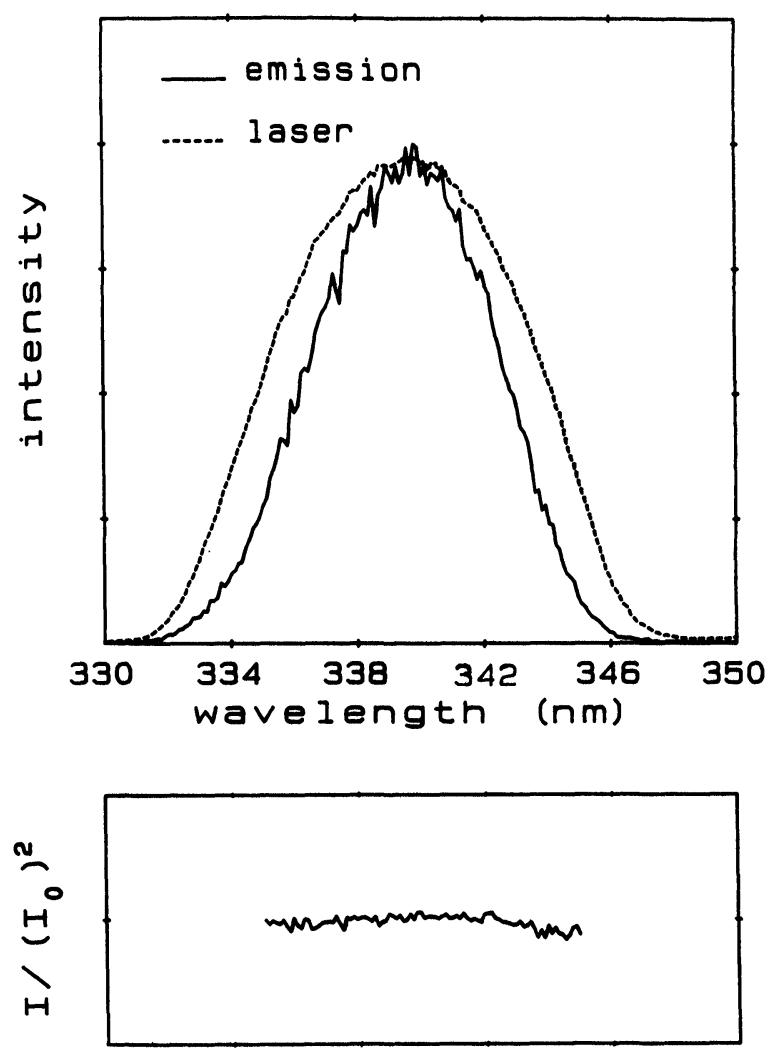

Figure 9 Wavelength and intensity dependence of $\mathrm{Xe}_{2} \mathrm{Br}$ emission obtained from a $1 \mathrm{mM}$ solution of $\mathrm{Br}_{2}$ in liquid xenon. In the top panel, both emission intensity (solid line) and the incident laser intensity (dotted line) are shown. In the bottom panel a plot of $I / I_{o}^{2}$ is shown, the ordinate is arbitrary, the abscissa is the same as in the top panel. 
from excitation spectra in solid xenon doped with atomic $\mathrm{Br}$ and reported in Table I to be near $310 \mathrm{~nm}$.)] Thus the sequential mechanism of dissociation followed by photo-association:

$$
\begin{aligned}
& \mathrm{Br}_{2}+\mathrm{h} v \longrightarrow \mathrm{Br}+\mathrm{Br} \\
& \mathrm{Br}+\mathrm{Xe}+\mathrm{h} v \longrightarrow \mathrm{Xe}^{+} \mathrm{Br}^{-}
\end{aligned}
$$

could not occur at these wavelengths-wavelengths longer than $\sim 330 \mathrm{~nm}$. The observed two-photon transition is a direct intermolecular charge transfer between $\mathrm{Br}_{2}$ and $\mathrm{Xe}$. As in any two-photon transition, we expect cross sections to be enhanced by intermediate state resonances. The cooperative two-electron transition

$$
\mathrm{Xe} \cdots \mathrm{Br}_{2}\left[\stackrel{\mathrm{h} v}{\longrightarrow} \mathrm{Xe} \cdots \mathrm{Br}_{2}^{*} \stackrel{\mathrm{h} v}{\longrightarrow}\right] \mathrm{Xe}^{+} \ldots \mathrm{Br}_{2}^{-}
$$

in which a photon is resonant with the promotion of an electron in $\mathrm{Br}_{2}$ to its antibonding state, $\mathrm{Br}_{2}^{*}$, and a second photon induces the transfer of an electron from $\mathrm{Xe}$ to $\mathrm{Br}_{2}^{*}$; provides a possible mechanism for resonant enhancement. Indeed, as the $\mathrm{Br}_{2}$ dissociative absorptions (which peak at $420 \mathrm{~nm}$ ) are approached, the two-photon transition probability increases - the exciplex photoproduction efficiency is $50 \%$ higher at $372 \mathrm{~nm}$ than at $350 \mathrm{~nm}$. Based on the u.v.-vis spectra discussed above, the two-photon threshold for all halogens in liquid xenon is $\sim 400 \mathrm{~nm}$. Since the dissociative absorptions in $\mathrm{Br}_{2}$ peak at $420 \mathrm{~nm}$, it is clear that the full benefit of the resonance in Eq. (9) cannot be realized in the case of $\mathrm{Br}_{2}$. However, resonant enhancement in both photons is possible in the case of $\mathrm{Cl}_{2}$.

In the case of $\mathrm{Cl}_{2}$, the dissociative ${ }^{1} \Pi \leftarrow \mathrm{X}$ transition peaks at $330 \mathrm{~nm}$, while the $\mathrm{XeCl}(\mathrm{B} \leftarrow \mathrm{X})$ transition peaks near $350 \mathrm{~nm}$ in unannealed solid xenon. ${ }^{12}$ Both are broad and therefore overlap. Thus in this case the two-electron transition is resonantly enhanced for both photons in the same spectral range. Such a resonance was most clearly demonstrated in the recent studies of $\mathrm{Xe}: \mathrm{Cl}_{2}$ van der Waals complexes. ${ }^{10}$ The coherent two-photon transition can be represented as:

$$
\mathrm{Xe} \cdots \mathrm{Cl}-\mathrm{Cl} \underset{330 \mathrm{~nm}}{\stackrel{\mathrm{h} v}{\longrightarrow}} \mathrm{Xe} \cdots \mathrm{Cl} \cdots \mathrm{Cl} \underset{350 \mathrm{~nm}}{\stackrel{\mathrm{h} v}{\longrightarrow}}] \mathrm{Xe}^{+} \ldots \mathrm{Cl}^{-} \ldots \mathrm{Cl}
$$

The action spectrum, the $\mathrm{Xe}_{2}^{+} \mathrm{Cl}^{-}$emission intensity divided by the square of the incident radiation intensity as a function of excitation wavelength, is shown in Figure 10. The spectrum shows a resonance near $340 \mathrm{~nm}$, a wavelength at which both steps in Eq. (10) are resonant. 


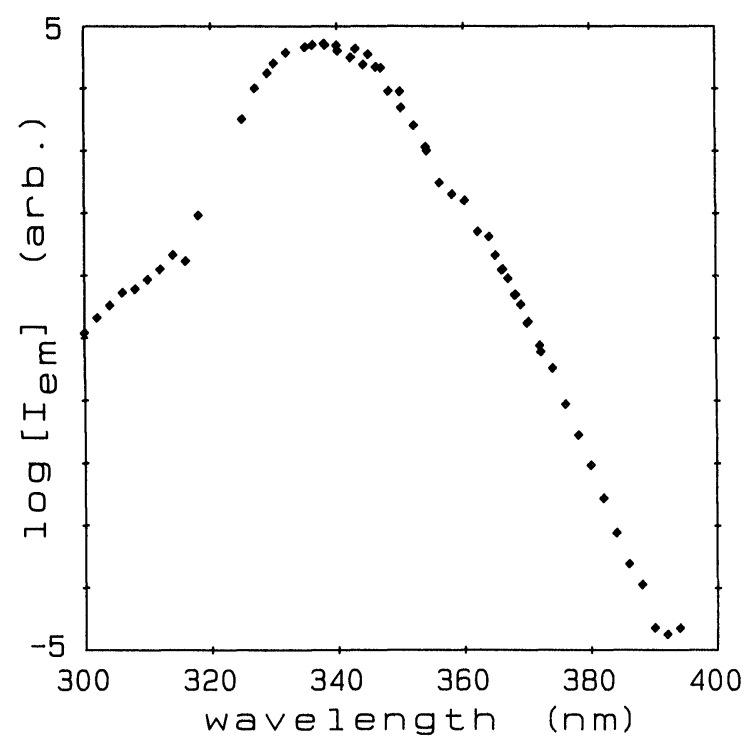

Figure 10 Action spectrum of $\mathrm{Xe}_{2} \mathrm{Cl}$ in $1 \mathrm{mM} \mathrm{Cl}_{2}: \mathrm{Xe}$ solution. The ordinate is the normalized logarithmic emission intensity, $I_{e m}=I_{f} / I_{t}^{2}$ in which $I_{f}$ is the fluorescence intensity and $I_{t}$ is the transmitted intensity. The data were obtained with an excimer pumped dye laser using several overlapping dyes.

Clearly, the coherent two-photon process of Eq. (10) is hard to distinguish from the sequential mechanism:

$$
\begin{aligned}
& \mathrm{Cl}_{2}+\mathrm{h} v \longrightarrow \mathrm{Cl}+\mathrm{Cl} \\
& \mathrm{Cl}+\mathrm{Xe}+\mathrm{h} v \longrightarrow \mathrm{Xe}^{+} \mathrm{Cl}^{-}
\end{aligned}
$$

The distinction is made by kinetic considerations supported by extensive fluence dependent emission and transmission measurements throughout the spectral range of the observed resonance. The fluence dependence of the exciplexic emission is second order throughout the spectral range, examples are provided in Figure 11b. This is not to be expected for the sequential mechanism. Only under special circumstances does the sequential mechanism yield a two-photon dependence - if the cross sections in the two steps are substantially different from each other, then a less than second order dependence should be observed. In the studied spectral region, both the dissociative absorption and the atomic charge transfer cross section change by 

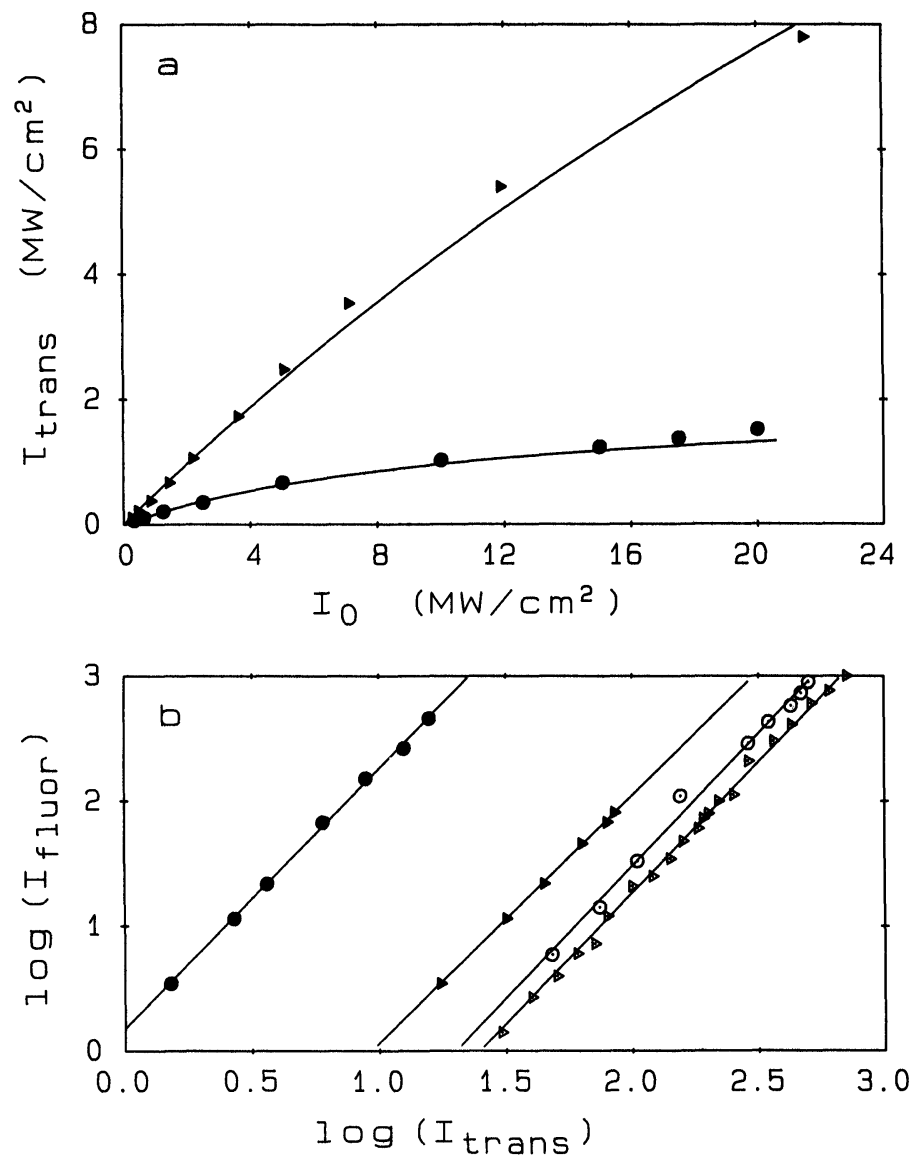

Figure 11 Transmission and exciplexic fluorescence intensities versus incident laser intensity, in a $1.3 \mathrm{mM}$ solution of $\mathrm{Cl}_{2}$ in Xe. (a) Transmission at $360 \mathrm{~nm}$ (filled triangles) and $340 \mathrm{~nm}$ (filled circles). The curves are the best fits to Eq. (12) in text. (b) Log-log plots of fluorescence intensity versus transmitted intensity, at different wavelengths: $340 \mathrm{~nm}$ (filled circles), $360 \mathrm{~nm}$ (filled triangles), $308 \mathrm{~nm}$ (open circles), $368 \mathrm{~nm}$ (open triangles). The slopes of the best fit lines in the same order are 2.07, 1.98, 2.11, 2.08.

at least an order of magnitude, yet the fluence dependence remains $2.05 \pm 0.07$ throughout.

Transmission measurements as a function of incident intensity are shown in Figure 11a for two different wavelengths. The data can be fitted by the assumption of two independent absorptions: a linear 
absorption, $\alpha$, that corresponds to the $\mathrm{Cl}_{2}\left({ }^{1} \Pi \leftarrow \mathrm{X}\right)$ transition; and a second order absorption, $\beta$, responsible for the formation of the exciplex. The transmitted intensity, $I$, is then given in terms of the incident intensity as:

$$
\mathrm{I}=\frac{\mathrm{I}_{\mathrm{o}} \alpha}{2 \beta \mathrm{I}_{\mathrm{b}}\left(\mathrm{e}^{\alpha \mathrm{c}}-1\right)-\alpha \mathrm{e}^{\alpha \mathrm{Cl}}}
$$

The fitted curves are also shown in Figure 11a. The derived values for $\alpha$ at 308,340 and $360 \mathrm{~nm}$ are $3.7 \times 10^{-19}, 5.6 \times 10^{-19}$ and $2.3 \times 10^{-19} \mathrm{~cm}^{2}$ respectively. These cross sections are approximately twice the known gas phase values for the $\mathrm{Cl}_{2}$ absorption. Due to the dielectric of the medium and the temperature of the solution $(200 \mathrm{~K})$ a $50 \%$ enhancement of the absorption is to be expected. Thus both in these measurements and also in the previous spectrometric measurements ${ }^{43}$ an anomalous enhancement of absorption cross sections is seen $(\sim 50 \%$ in the present). The derived second order absorption cross sections, $\beta$, at 308,340 and $360 \mathrm{~nm}$ are $5.9 \times 10^{-45}, 1.6 \times 10^{-44}$ and $2 \times 10^{-45} \mathrm{~cm}^{4} \mathrm{~s}$ respectively. These cross sections are thought to be more relaible than those previously reported from solid state measurements, ${ }^{12}$ since the latter are subject to several model assumptions. These cross sections are for truly cooperative transitions, minimally four-body processes, in which two photons induce a two-electron transition.

Finally, it should be pointed out that in the case of interhalogens, the two-photon two-electron cooperative absorption should provide a means of selectivity in the product branching ratio. As an example, in the case of ICl, which possesses continuous absorptions in the 200$600 \mathrm{~nm}$ range, selectivity of the production can be exercised by the resonance conditions of the second photon in the scheme of Eq. (10). Based on the solid state $\mathrm{B} \leftarrow \mathrm{X}$ absorptions of Table I, it can be predicted that the iodide channel should be enhanced near $280 \mathrm{~nm}$ while the chloride should be enhanced near $350 \mathrm{~nm}$. These predictions have already been verified. ${ }^{41}$

\section{CONCLUDING REMARKS}

Rare gas solids and liquids constitute model systems for the study of condensed phase dynamics. Photo-induced harpooning provides a powerful experimental tool for the investigation of reactive molecular 
dynamics in these media. These principles were illustrated through selected examples of studies in rare gas matrices and liquids. Serious progress in understanding the many-body dynamics in these dense media will require a joint effort between theory and experiment. As a result of such an effort, the first detailed theoretical treatment of dynamics in rare gas solids-Molecular Dynamics simulations of HI photodissociation in crystalline xenon-was recently reported,${ }^{44}$ and preliminary experiments on the same system recently completed..$^{42} \mathrm{We}$ hope that the exposition in this article will serve as a motivation for fostering such activities in the future.

\section{Acknowledgement}

This research is supported in part by the US Air Force Astronautics Laboratory under contract F04611-87-K-0024.

\section{References}

1. S. I. Yakovlenko, Sov. J. Quant. Electron. 8, 151 (1978).

2. V. A. Dubov, L. I. Gudzenko, L. V. Gurvich and S. I. Yakovlenko, Chem. Phys. Lett. 45, 330 (1977); 46, 25 (1977).

3. H. P. Grieneissen, Hu Xue-Jing and K. L. Kompa, Chem. Phys. Lett. 82, 421 (1981).

4. V. S. Dubov, Ya. E. Lapsker, A. N. Samoilova and L. V. Gurvich, Chem. Phys. Lett. 83, 518 (1981).

5. B. E. Wilcomb and R. Burnham, J. Chem. Phys. 74, 6784 (1981).

6. Y. C. Yu, D. W. Setser and H. Horiguchi, J. Phys. Chem. 87, 2209 (1983).

7. J. K. Ku, G. Inoue and D. W. Setser, J. Phys. Chem. 87, 2989 (1983).

8. D. W. Setser and J. K. Ku, in Photophysics and Photochemistry Above $6 \mathrm{eV}$, edited by F. Lahmani (Elsevier, New York, 1985).

9. M. Boivineau, J. LeCalve, M. C. Castex and C. Jouvet, Chem. Phys. Lett. 128, 528 (1986); J. Chem. Phys. 84, 4712 (1986).

10. C. Jouvet, M. Boiveneau, M. C. Duval and B. Soep, J. Phys. Chem. 91, 5416 (1987).

11. D. L. Andrews and M. J. Harlow, J. Chem. Phys. 87, 1088 (1983); J. Chem. Phys. 80, 4753 (1984).

12. M. E. Fajardo and V. A. Apkarian, J. Chem. Phys. 85, 5660 (1986).

13. M. E. Fajardo and V. A. Apkarian, Chem. Phys. Lett. 134, 51 (1987).

14. L. Wiedeman, M. E. Fajardo, V. A. Apkarian, Chem. Phys. Lett. 134, 55 (1987).

15. L. Wiedeman, M. E. Fajardo, V. A. Apkarian, J. Phys. Chem. 92, 342 (1988).

16. M. E. Fajardo, L. Wiedeman and V. A. Apkarian, Proceedings of IQEC, Baltimore, 1987; Post Deadline Report, PD-16.

17. H. Jara, H. Pummer, H. Egger and C. K. Rhodes, Phys. Rev. B30, 1 (1984).

18. M. Shahid, H. Jara, H. Pummer, H. Egger and C. K. Rhodes, Opt. Lett. 10, 448 (1985). 
19. T. R. Loree, R. R. Showalter, T. M. Johnson, B. S. Birmingham and W. M. Hughes, Opt. Lett. 11, 510 (1986).

20. V. E. Bondybey and L. E. Brus, J. Chem. Phys. 65, 620 (1975); J. Chem. Phys. 64, 3724 (1976).

21. V. E. Bondybey and C. Fletcher, J. Chem. Phys. 64, 3615 (1976).

22. V. E. Bondybey, S. S. Bearder and C. Fletcher, J. Chem. Phys. 64, 5243 (1976).

23. L. E. Brus and V. E. Bondybey, J. Chem. Phys. 65, 71 (1976); Chem. Phys. Letts. 36, 252 (1975).

24. P. Beeken, M. Mandich and G. Flynn, J. Chem. Phys. 76, 5995 (1982); M. Mandich, P. Beeken and G. Flynn, J. Chem. Phys. 77, 702 (1982).

25. P. B. Beeken, E. A. Hanson and G. W. Flynn, J. Chem. Phys. 78, 5892 (1983).

26. B. S. Ault, W. F. Howard, Jr. and L. Andrews, J. Mol. Spectr. 55, 217 (1975).

27. J. Fournier, F. Salama and R. J. Le Roy, J. Phys. Chem. 89, 3530 (1985); F. Salama and J. Fournier, Chem. Phys. Letts. 120, 35 (1985).

28. F. Salama, Thesis University of Paris (1986).

29. J. LeCalve and M. Chergui, Chem. Phys. Letts. 132, 256 (1986).

30. P. Gurtler, HASYLAB annual report, 76 (1985).

31. B. S. Ault and L. Andrews, J. Chem. Phys. 64, 3075 (1976); J. Chem. Phys. 65, 4192 (1976).

32. M. E. Fajardo and V. A. Apkarian, "Charge transfer photodynamics in halogen doped xenon matricesII: photoinduced harpooning and the delocalized charge transfer states of solid xenon halides $(\mathrm{F}, \mathrm{Cl}, \mathrm{Br}, \mathrm{I})$ " J. Chem. Phys. (submitted, 1988).

33. I. Last and T. F. George, J. Chem. Phys. 86, 3787 (1987).

34. I. Last and T. F. George, J. Chem. Phys. 87, 1183 (1987).

35. I. Last, T. F. George, M. E. Fajardo and V. A. Apkarian, J. Chem. Phys. 87, 5917 (1987).

36. I. Last, Y. S. Kim and T. F. George, Chem. Phys. Lett. 138, 225 (1987).

37. M. E. Fajardo and V. A. Apkarian, "Energy storage and thermoluminescence in halogen doped solid xenon III. Photodynamics of charge separation, trapping and ion-hole recombination" J. Chem. Phys. (submitted, 1988).

38. S. D. Druger and R. S. Knox, J. Chem. Phys. 50, 3143 (1969).

39. M. Umehara, Phys. Rev. B33, 4237 (1986); Phys. Rev. B33, 4245 (1986).

40. L. Y. Nelson and G. C. Pimentel, Inorg. Chem. 6, 1758 (1967); D. Boal and G. A. Ozin, Spectroscopy Letts. 4, 43 (1971); W. F. Howard, Jr. and L. Andrews, J. Am. Chem. Soc. 96, 7864 (1974); I. R. Beattie, A. German, H. E. Blayden and S. B. Brumbach, J. Chem. Soc. Dalton 1659 (1975).

41. F. Okada, L. Wiedeman and V. A. Apkarian, submitted for publication, J. Phys. Chem. (1988).

42. F. Okada, W. Lawrence and V. A. Apkarian, submitted for publication, Chem. Phys. Lett. (1988).

43. M. E. Fajardo, V. A. Apkarian, A. Moustakas, H. Krueger and W. Weitz, J. Phys. Chem. 92, 357 (1988).

44. R. Alimi, R. B. Gerber and V. A. Apkarian, J. Chem. Phys. in press (1988). 